\title{
Increasing fruit and vegetable intake decreases inflammation in an older population
}

\author{
N. Nadeem, J. Woodside, C. Neville, S. Gilchrist, I. Young and J. McEneny \\ Centre for Public Health, Nutrition and Metabolism Group, Queen's University, Belfast, BT12 6BJ, UK
}

CVD is the leading cause of morbidity and mortality in developed countries, and chronic inflammation plays a major role in its development. As CVD risk and inflammation increases with age, older people now account for the majority of CVD morbidity worldwide $^{(1)}$. Conversely, increased fruit and vegetable $(\mathrm{F} \& \mathrm{~V})$ intake has been suggested to correlate with reduced CVD risk ${ }^{(2)}$, although direct trial evidence of their ability to influence markers of inflammation is lacking.

To assess if increased F\&V intake reduces serum amyloid-A (SAA), in serum and $\mathrm{HDL}_{2 \& 3}$ and if this latter enhances the antiatherogenic properties of $\mathrm{HDL}_{2 \& 3}$.

Subjects aged between 65 to 85 years were randomised to 2 or 5 portions of F\&Vs per day, for 16 -weeks ( $n=38$ per group). HDL $2 \& 3$ were isolated by rapid ultracentrifugation. Serum-hsCRP was measured by an immuoturbimetric assay, serum-IL-6, e-selectin, SAA and $\mathrm{HDL}_{2 \& 3}$-SAA were measured by ELISA procedures, and $\mathrm{HDL}_{2 \& 3}$-CETP activity was measured by a fluorometric assay.

These results demonstrated that hsCRP, IL-6 and e-selectin were unchanged following either the 2 or 5 portion interventions. However, following the 5-portion intervention, SAA significantly decreased in serum at weeks 12 and 16 , in $\mathrm{HDL}_{2}$ at weeks 6,12 and 16 and in $\mathrm{HDL}_{3}$ at weeks 12 and 16 (table 1), which was accompanied by a decrease in the activity of CETP in $\mathrm{HDL}_{2}$ at weeks 6,12 and 16 ( $p=0.03,0.02$ and 0.001 , respectively). Additionally, in the between group analyses ( 2 vs. 5 portions), SAA decreased in serum at week 12, in $\mathrm{HDL}_{2}$ at weeks 6 and 16 and in $\mathrm{HDL}_{3}$ at weeks 12 and 16 (table 1). Additionally, CETP activity decreased in $\mathrm{HDL}_{2}$ at week $16(p=0.03)$.

Table 1. SAA changes and statistical differences following F\&V intervention

Results were logarithmically transformed and are summarised as mean geometric change from baseline (IQ range). P1 pre vs. post 5-portion intervention: P2 between group statistics $(2$ vs. 5 portion change)

\begin{tabular}{|c|c|c|c|c|c|c|c|c|c|}
\hline \multirow[b]{2}{*}{ Week } & \multicolumn{3}{|c|}{ Change in (5-portion group) } & \multicolumn{3}{|c|}{ P1 } & \multicolumn{3}{|c|}{$\mathbf{P 2}$} \\
\hline & 6 & 12 & 16 & 6 & 12 & 16 & 6 & 12 & 16 \\
\hline Serum $\mu \mathrm{mol} / \mathrm{L}$ & $0.83(0.7,1.1)$ & $0.73(0.6,0.9)$ & $0.76(0.6,1.0)$ & 0.13 & 0.04 & 0.05 & 0.23 & 0.04 & 0.31 \\
\hline $\mathrm{HDL}_{2} \mu \mathrm{mol} / \mathrm{mg}$ protein & $0.75(0.6,0.9)$ & $0.71(0.5,0.1)$ & $0.51(0.4,0.7)$ & 0.01 & 0.02 & 0.001 & 0.01 & 0.08 & 0.001 \\
\hline $\mathrm{HDL}_{3} \mu \mathrm{mol} / \mathrm{mg}$ protein & $0.86(0.9,1.1)$ & $0.65(0.5,0.9)$ & $0.64(0.5,0.9)$ & 0.17 & 0.001 & 0.008 & 0.07 & 0.01 & 0.008 \\
\hline
\end{tabular}

These results have identified: i) SAA responds to increased F\&V intake, where other markers of inflammation/endothelial activation were unresponsive. ii) Increased $\mathrm{F} \& \mathrm{~V}$ intake lowered systemic and HDL-associated inflammation, and this latter influenced the antiatherogenic properties of $\mathrm{HDL}_{2 \& 3}$. Overall, these results provide tangible evidence of the effectiveness of increasing $\mathrm{F} \& \mathrm{~V}$ intake on inflammation and possible CVD risk in an older population.

This work was funded by the Food Standards Agency and the Department of Health, UK.

1. Man JP \& Jugdutt BI (2011) Heart Fail Rev (Epub ahead of print).

2. He FJ, Nowson CA \& MacGregor GA (2006) Lancet 367, 320-326. 